\title{
ADEQUAÇÃO ÀS NORMAS E QUALIDADE DA MADEIRA SERRADA PARA FINS ESTRUTURAIS COMERCIALIZADA NO DISTRITO FEDERAL
}

\author{
Vitor Martim de Oliveira*, Cláudio Henrique Soares Del Menezzi**, José Arlete Alves Camargos***, \\ Ailton Teixeira do Vale** \\ *Eng. Florestal, Departamento de Engenharia Florestal, UNB - vitorflorestal@hotmail.com \\ **Eng. Florestal, Dr., Departamento de Engenharia Florestal, UNB - cmenezzi@unb.br - ailtontv@unb.br \\ ***Administrador, M.Sc., Laboratório de Produtos Florestais, IBAMA - jose.arlete@ibama.gov.br \\ Recebido para publicação: 14/08/2007 - Aceito para publicação: 16/12/2007
}

\begin{abstract}
Resumo
Este trabalho foi realizado em madeireiras do Distrito Federal, com o objetivo de avaliar a qualidade da madeira serrada comercializada para fins estruturais. Foram visitadas 30 empresas, o que corresponde a $20 \%$ do total de empresas registradas junto ao sindicato patronal. Foram feitas medições da bitola das principais peças de madeira comercializadas e coletadas amostras para identificação botânica e determinação do teor de umidade. As bitolas e a nomenclatura das peças foram comparadas ao disposto para peças de madeira serrada relacionadas nas normas 7203/1982, 7190/1997, 14807/2002 da ABNT. Foram identificadas 18 espécies de madeira, sendo o angelimvermelho (Dinizia excelsa) a mais comercializada. Verificou-se que a maioria dos empresários desconhece as normas brasileiras para madeira serrada e que elas não são adotadas largamente no processo produtivo. O teor de umidade médio observado foi de $13,4 \%$, o que está na faixa de teor de umidade de equilíbrio para o Distrito Federal, no entanto, $20 \%$ das peças ficaram fora dessa faixa. Observou-se que quase $27 \%$ das empresas não identificam as espécies botânicas corretamente. Verificou-se, ao analisar outras normas da ABNT, que elas entram em conflito ao especificar bitolas e nomenclaturas.
\end{abstract}

Palavras-chave: Normalização; madeira serrada; madeira estrutural.

\begin{abstract}
Suitability of the Brazilian standards and quality of the sawnwood for structural purposes traded in Distrito Federal. This work aimed at evaluating the suitability and quality of the sawnwood traded for structural purposes in Distrito Federal. Thirty companies were visited, which corresponded to $20 \%$ of total companies registered at the wood companies union. Measurements of the wood pieces were made and wood samples were collected for anatomical identification and moisture content determination. The measures and the nomenclature of the wood pieces were compared to those listed on the following Brazilian standards (ABNT): 7203/1982, 7190/1997 and 14807/2002. Eighteen wood species were identified and the most common was Dinizia excelsa (angelim), but $26.7 \%$ had been wrongly identified by the owners. It was verified that most of the owners did not know about the Brazilian standards for sawnwood and, this way, they are not used in the productive process. The moisture content (MC) of the traded wood was about $13.4 \%$, which means that the wood was in a dry condition according to the expected equilibrium moisture content (EMC) of the Distrito Federal. However, 20\% of the pieces had $\mathrm{MC}$ higher than EMC, and could be considered in wet condition. When the Brazilian standards were analyzed it was observed a severe conflict for the wood measures and nomenclatures.

Keywords: Standardization; sawnwood; structural wood.
\end{abstract}

\section{INTRODUÇ̃̃̃}

Acredita-se que um problema comum no mercado de madeira serrada seja a falta de padronização das peças e a não-observância às normas que regulamentam o setor. Ademais, a identificação equivocada das espécies botânicas comercializadas é uma limitação usual e, dessa forma, o 
consumidor pode comprar peças de madeira de qualidade inferior. Mesmo diante dessas limitações, de acordo com Gesualdo (1998), o emprego de madeira de forma definitiva na habitação vem se mantendo crescente, inclusive a despeito dos conhecidos preconceitos inerentes à madeira, sempre relacionados à insuficiente divulgação das informações de projetos específicos, desenvolvidos por profissionais habilitados. Segundo Atanasov (2001), no segmento da construção civil, a falta de padronização quanto à qualidade, bitolas e comprimentos pode ser responsável por $23,5 \%$ dos problemas relacionados à madeira, que foram constatados junto às revendas.

Em estudo feito pelo Imazon em 2005, junto a produtores de madeira do norte do Brasil, a qualidade do produto foi apontada como a maior exigência dos compradores nacionais e internacionais. Em seguida, apareceram exigências como preços competitivos e pontualidade na entrega. Por outro lado, foi identificado que os empresários acreditam que a origem legal e a certificação florestal são exigências menos importantes (REVISTA DA MADEIRA, 2006).

Para Pio et al. (2004), no mercado interno a situação é preocupante, pois só é vendido produto de qualidade aquém do necessário ao uso final. É conveniente rever os critérios que serviram para estipular as normas e conduzir os empresários à sua aceitação, contribuindo com a minimização da geração de resíduos.

O objetivo primeiro da normalização pode resumir-se ao seguinte: maior qualidade pelo menor custo. Daí deriva outra série de vantagens, entre as quais se poderiam citar a confiança do usuário nos elementos normalizados, a permutabilidade dos produtos utilizados e maior facilidade, presteza e qualidade dos trabalhos realizados (MASCARÓ, 1975).

Com o intuito de proporcionar ao consumidor a oportunidade de aquisição de um produto mais adequado e incentivar uma consciência empreendedora e responsável nos empresários, a partir das vantagens econômicas decorrentes do cumprimento das normas, este trabalho teve como objetivo realizar um diagnóstico da qualidade da madeira serrada estrutural comercializada no Distrito Federal. Para tanto, foi avaliado o grau de conhecimento e aplicação das normas brasileiras e da qualidade das madeiras comercializadas. Foi realizado, também, um levantamento das características do empresário local e a sua opinião a respeito da normalização.

\section{MATERIAIS E MÉTODOS}

\section{Amostragem}

Foram selecionadas aleatoriamente 30 empresas do ramo madeireiro do Distrito Federal, o que correspondeu a $20 \%$ do total das empresas filiadas ao sindicato patronal (SINDIMAM-DF). Para cada empresa selecionada, foi aplicado um questionário para coleta de informações sobre a caracterização da madeira comercializada, da adequação às normas, do perfil das empresas e do grau de conhecimento das normas brasileiras de madeira serrada.

\section{Caracterização da madeira}

Foram coletadas 30 amostras das peças de madeira para identificação macroscópica e determinação de teor de umidade. No momento da coleta foi perguntado ao empresário o nome vulgar da espécie comercializada e a nomenclatura utilizada para identificar a bitola da peça. Os nomes vulgares declarados foram utilizados para localizar o nome científico da espécie segundo o disposto em Camargos et al. (2001). Em seguida, as amostras de madeira coletadas foram identificadas macroscopicamente por meio da comparação com o material disponível na Xiloteca do Setor de Anatomia da Madeira do Laboratório de Produtos Florestais do Instituto Brasileiro do Meio Ambiente e dos Recursos Naturais Renováveis. Após essa identificação, o teor de umidade foi determinado segundo a NBR7190 (1997). Informações relativas à densidade e à resistência à compressão paralela das espécies declaradas e das identificadas foram obtidas em IBDF (1981), IBDF (1988) e IBAMA (1997).

\section{Adequação às normas}

A nomenclatura das peças declarada pelo empresário foi comparada com a relacionada na norma NBR 7203 (1982): pranchão, prancha, viga, vigota, caibro, tábua, sarrafo e ripa. Essa norma foi considerada a principal referência para as comparações de nomenclaturas e bitolas. Porém, foram também realizadas comparações com as normas NBR 7190 (1997), que estabelece bitolas mínimas de madeira 
para uso estrutural, e NBR 14807 (2002), a qual também estabelece nomenclaturas e bitolas para madeira serrada.

\section{Perfil das empresas}

O questionário aplicado continha perguntas relativas ao grau de conhecimento e à opinião dos empresários em relação à normalização. Também foram investigadas as causas de insatisfações de seus clientes. Para as questões em que a resposta poderia ser múltipla, foi adotado o cálculo da freqüência relativa, que foi a somatória das respostas dadas para um determinado item sobre a somatória de todos os itens respondidos, similar ao feito por Del Menezzi e Bonduelle (2002), conforme a equação abaixo:

$$
F R(\%)=\frac{\sum_{i=1}^{n} p i}{\sum_{i}^{n} p i} \times 100
$$

Em que:

$\mathrm{p}=$ resposta dada $\boldsymbol{i}$, que poderia ser produtos comercializados, origem da madeira, etc.

$\mathrm{i}=1 \ldots \boldsymbol{n}$.

\section{RESULTADOS E DISCUSSÃO}

\section{Perfil das empresas e espécies comercializadas}

Metade das empresas relatou já ter recebido reclamações de clientes sobre a madeira serrada. A reclamação mais comum trata-se da falta de precisão das medidas e de bitolas inadequadas. Essa insatisfação dos clientes correspondeu a $58 \%$ do total de reclamações. Também foram relatadas reclamações sobre a identificação das espécies e o teor de umidade das madeiras. A figura 1 mostra a freqüência de cada tipo de insatisfação.

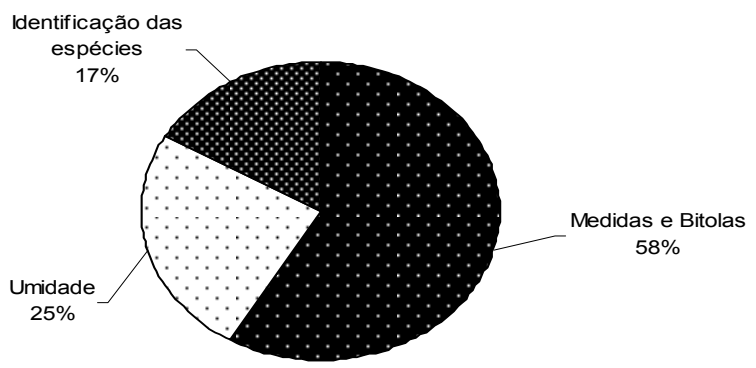

Figura 1. Distribuição dos diferentes tipos de reclamações de clientes relatados pelas empresas.

Figure 1. Distribution of the client's complaints.

Considerando que problemas com as dimensões e a umidade das peças estão mais relacionados ao processo produtivo, sendo assim uma questão de qualidade do produto, e que problemas com a identificação da madeira são relativos mais a uma falta de informação no setor de revenda, observa-se que a qualidade do produto é responsável pela maioria das insatisfações dos consumidores de madeira serrada.

Apenas 13,3\% dos proprietários das empresas declararam ter conhecimento da Norma NBR 7203 da ABNT. Até mesmo entre as empresas especializadas apenas em madeira serrada, das quais poderia se esperar um nível superior de informação, os resultados não foram melhores.

Em todas as empresas, apenas os nomes populares das madeiras eram fornecidos, isso devido ao desconhecimento dos nomes científicos de cada espécie. Foram relatadas 18 espécies de madeira comercializadas como madeira estrutural no Distrito Federal, porém apenas cinco espécies dominam o mercado e são encontradas mais freqüentemente: angelim-vermelho (Dinizia excelsa), maçaranduba 
(Manilkara huberi), ipê (Tabebuia sp.), cumaru (Dipteryx odorata) e melancieira (Alexa grandiflora). Essas espécies foram relatadas como presentes em mais de $92 \%$ dos estabelecimentos. Entretanto, a espécie mais freqüente foi o angelim-vermelho (Dinizia excelsa), presente em 73,3\% dos estabelecimentos. Supõe-se que o motivo principal seja o preço da espécie, que é consideravelmente inferior ao de espécies também utilizadas em estruturas, como o ipê e o cumaru.

Ao confrontar as nomenclaturas obtidas nas madeireiras com as nomenclaturas geradas por identificação botânica, realizada em laboratório, chegou-se a um índice de 26,7\% de identificações equivocadas. Esse índice pode ser considerado elevado e indica que ao menos $1 / 4$ das espécies está sendo comercializado equivocadamente. Ademais, na maioria dos equívocos, a espécie anunciada pela empresa madeireira possuía valores de densidade e resistência à compressão paralela superiores aos valores da espécie verdadeira, como pode ser observado na tabela 1. São apresentados os valores de compressão paralela, porque ela é a principal propriedade mecânica, segundo a NBR 7190. Dessa forma, o consumidor, na sua maioria leigo, pode estar adquirindo um produto de qualidade inferior à desejada, vindo a utilizar peças estruturais de madeira com propriedades físicas e mecânicas insuficientes para o que se propõe, podendo acarretar sérios acidentes.

Tabela 1. Identificação anatômica e comparação de propriedades físicas e mecânicas das amostras reprovadas.

Table 1. Anatomical identification of the wood and related physical and mechanical properties.

\begin{tabular}{|c|c|c|c|c|c|c|}
\hline Amostra & $\begin{array}{l}\text { Espécie anunciada } \\
\text { pelo vendedor }\end{array}$ & $\begin{array}{c}\text { Densidade } \\
12 \% \\
\left(\mathrm{~kg} / \mathrm{m}^{3}\right) \\
\end{array}$ & $\begin{array}{c}\text { Compressão } \\
\text { paralela - } \\
\mathbf{f}_{\mathrm{c}, 0}\left(\mathrm{kgf} / \mathrm{cm}^{2}\right)\end{array}$ & Espécie correta & $\begin{array}{c}\text { Densidade } \\
12 \% \\
\left(\mathbf{k g} / \mathbf{m}^{3}\right) \\
\end{array}$ & $\begin{array}{c}\text { Compressão } \\
\text { paralela - } \\
\mathbf{f}_{\mathrm{c}, 0}\left(\mathrm{kgf} / \mathrm{cm}^{2}\right)\end{array}$ \\
\hline 2 & $\begin{array}{c}\text { Cumaru } \\
\text { Dipteryx odorata }\end{array}$ & 1080 & 987 & $\begin{array}{c}\text { Cuiarana } \\
\text { Terminalia amazonica }\end{array}$ & 800 & 795 \\
\hline 4 & $\begin{array}{l}\text { Sapucaia } \\
\text { Lecythis paraensis }\end{array}$ & 1000 & 716 & $\begin{array}{c}\text { Abiurana } \\
\text { Micropholis sp. }\end{array}$ & 790 & 662 \\
\hline 8 & $\begin{array}{l}\text { Melancieira } \\
\text { Alexa grandiflora }\end{array}$ & 600 & 594 & $\begin{array}{c}\text { Parinari } \\
\text { Parinari excelsa }\end{array}$ & 792 & 600 \\
\hline 13 & $\begin{array}{l}\text { Angelim-vermelho } \\
\text { Dinizia excelsa }\end{array}$ & 990 & 873 & $\begin{array}{l}\text { Breu vermelho } \\
\text { Tetragastris altissima }\end{array}$ & 790 & 779 \\
\hline 15 & $\begin{array}{c}\text { Cumaru } \\
\text { Dipteryx odorata }\end{array}$ & 1080 & 987 & $\begin{array}{l}\text { Goiabão } \\
\text { Pouteria } \text { sp. }\end{array}$ & 920 & 804 \\
\hline 16 & $\begin{array}{l}\text { Tuturubá } \\
\text { Conepia oiti }\end{array}$ & 700 & 658 & $\begin{array}{c}\text { Cupiúba } \\
\text { Goupia glabra }\end{array}$ & 840 & 689 \\
\hline 25 & $\begin{array}{c}\text { Ipê } \\
\text { Tabebuia sp. }\end{array}$ & 1050 & 1021 & $\begin{array}{l}\text { Angelim-vermelho } \\
\text { Dinizia excelsa }\end{array}$ & 990 & 873 \\
\hline 30 & $\begin{array}{c}\text { Maçaranduba } \\
\text { Manikara huberi }\end{array}$ & 1070 & 1109 & $\begin{array}{c}\text { Angelim-vermelho } \\
\text { Dinizia excelsa }\end{array}$ & 990 & 873 \\
\hline
\end{tabular}

IBAMA (1997), IBDF (1988) e IBDF (1981).

\section{Umidade da madeira serrada}

A umidade média encontrada nas amostras coletadas foi de $13,4 \%$, a qual é desejável para o Distrito Federal, que possui teor de umidade de equilíbrio (TUE) médio de 12,2\%, segundo Galvão e Jankowsky (1988). Entretanto, seis amostras, ou 20\% do total, ultrapassaram o TUE máximo para madeiras em Brasília, que é de $15,8 \%$, conforme esses autores.

Verificou-se durante as visitas que 33,3\% das empresas não armazenam adequadamente os seus estoques de madeira. Nesses casos, observou-se que a cobertura é parcial e ou ineficiente, ou simplesmente as peças são empilhadas em pátios sem nenhuma cobertura contra sol e chuva. A tabela 2 mostra a relação entre o teor de umidade e a condição de armazenamento das amostras reprovadas.

\section{Nomenclatura das peças de madeira}

Quando confrontadas as nomenclaturas fornecidas pelas empresas, as peças de madeira medidas e as nomenclaturas estabelecidas pela norma NBR 7203 da ABNT, chegou-se a um índice de 23,7\% de reprovação. Esse resultado não necessariamente representa uma atitude de má-fé dos empresários, uma vez que muitas das ocorrências de reprovação aconteceram por exceder as dimensões máximas estipuladas pela norma. Os números não revelam o grau em que essas nomenclaturas são ignoradas por 
empresários, trabalhadores das madeireiras e consumidores. Nomenclaturas oficiais são abandonadas e, simplesmente, medidas de seção transversal assumem esse papel na comunicação, tanto entre pessoas do ramo como entre consumidores e lojistas. Segundo Atanasov (2001), embora haja normas da ABNT especificando dimensões e nomes das peças, elas são ignoradas pelos setores de produção e comércio de madeira serrada e beneficiada. Freqüentemente, observou-se que empresários e trabalhadores não vêem, nas suas concepções de nomenclaturas, diferenças entre pranchão, prancha, viga e vigota. $\mathrm{O}$ mesmo foi observado para a relação entre sarrafo e ripa.

Tabela 2. Umidade e condição de armazenamento das amostras reprovadas.

Table 2. Moisture content and storing conditions of the non-approved wood samples.

\begin{tabular}{lcccc}
\hline Amostra & Nome popular & Nome científico & Umidade (\%) & Tipo de depósito \\
\hline 1 & Angelim-vermelho & Dinizia excelsa & 15,9 & Descoberto \\
2 & Cuiarana & Terminalia amazonica & 16,1 & Coberto \\
3 & Angelim-vermelho & Dinizia excelsa & 16,3 & Coberto \\
15 & Goiabão & Pouteria sp. & 22,9 & Descoberto \\
17 & Melancieira/Mista/Taipá & Alexa grandiflora & 17,9 & Descoberto \\
19 & Melancieira/Mista/Taipá & Alexa grandiflora & 16,4 & Coberto \\
\hline
\end{tabular}

Reprovações por segurança

Embora muitas reprovações por nomenclatura tenham ocorrido por excederem as dimensões máximas, não foram poucas as situações em que a reprovação se deu pelo fato de a peça não ter atingido as dimensões mínimas estipuladas pela norma. Isso pode ser considerado como um resultado muito negativo, uma vez que essa insuficiência de dimensões mínimas ocorre em peças estruturais, estando assim estreitamente ligadas à segurança das pessoas. O percentual relativo a essa reprovação foi de $10,5 \%$ do total de amostras medidas, o que equivale a $44,2 \%$ das reprovações por nomenclatura. A tabela 3 apresenta as medições de seção transversal que ficaram abaixo do limite inferior das dimensões propostas pela norma NBR 7203 da ABNT.

Tabela 3. Medidas das peças reprovadas por segurança.

Table 3. Actual size of the wood samples non-approved by safety reasons.

\begin{tabular}{|c|c|c|c|c|c|c|c|c|}
\hline Peças & Pranchão & Prancha & Viga & Vigota & Caibro & Tábua & Sarrafo & Ripa \\
\hline$(\mathrm{cm})$ & Esp / Larg & Esp / Larg & $\begin{array}{c}\text { Esp / Larg } \\
>4,0 /\end{array}$ & Esp / Larg & Esp / Larg & Esp / Larg & Esp / Larg & $\begin{array}{l}\text { Esp / } \\
\text { Larg }\end{array}$ \\
\hline $\begin{array}{l}\text { NBR - } \\
7203\end{array}$ & $\begin{array}{c}>7,0 />20,0 \\
6,0 / 44,0 \\
4,0 / 57,4 \\
4,5 / 41,0 \\
4,0 / 51,0 \\
4,0 / 40,2 \\
3,9 / 30,4 \\
6,8 / 52,0 \\
3,8 / 44,0\end{array}$ & $\begin{array}{c}4,0-7,0 /> \\
20,0 \\
8,2 / 19,8 \\
3,9 / 33,7\end{array}$ & $\begin{array}{c}11,0- \\
20,0 \\
5,2 / 10,8\end{array}$ & $\begin{array}{c}4,0-8,0 / \\
8,0-11,0 \\
5,0 / 7,8 \\
3,9 / 8,2\end{array}$ & $\begin{array}{c}4,0-8,0 / \\
5,0-8,0 \\
4,8 \text { / 4,9 } \\
5,8 \text { / 4,9 } \\
4,7 \text { / 4,7 } \\
4,3 \text { / 4,8 } \\
3,8 \text { / 4,9 }\end{array}$ & $\begin{array}{c}1,0-4,0 / \\
>10,0\end{array}$ & $\begin{array}{c}2,0-4,0 / \\
2,0-10,0 \\
1,5 / 6,2 \\
1,5 \text { / 5,0 } \\
1,7 / 5,1 \\
1,7 \text { / 5,1 } \\
1,3 \text { / 4,9 }\end{array}$ & $\begin{array}{c}<2,0 /< \\
10,0\end{array}$ \\
\hline
\end{tabular}

\section{Dimensões padrões de madeira serrada}

Ao confrontar as bitolas encontradas nas empresas com as bitolas sugeridas pela norma NBR 7203 , verificou-se que $98,6 \%$ das peças medidas não estão de acordo com nenhuma das bitolas sugeridas pela norma. De 219 medições de seção transversal, apenas 3 conferem com as estabelecidas pela ABNT. De fato, a norma não é muito clara ao estipular os padrões de bitola de madeira serrada, uma vez que não diferencia pranchão de prancha e viga de vigota. Porém não se justifica tamanha discrepância dos resultados, dado que a intensidade de resultados negativos também se repete nas demais peças estudadas, sobre as quais a norma não é falha. Ressalta-se que neste estudo apurou-se que apenas 13,3\% das empresas têm conhecimento da norma em questão. Entretanto, apenas 1,3\% do resultado foi aprovado. 


\section{Normas relevantes}

Atualmente, além da NBR 7203, as normas NBR 7190 e NBR 14807 também regulamentam dimensões e nomenclaturas para madeira serrada de folhosas.

\section{Dimensões mínimas de peças estruturais (NBR 7190)}

Em relação a essa norma, as peças de madeira são classificadas somente como peças principais e peças secundárias. Apenas vigas e vigotas são consideradas peças principais, e apenas caibros e ripas recebem a denominação de peças secundárias. As peças principais obtiveram uma reprovação de $16,7 \%$ no item área mínima e 8,3\% quanto à espessura mínima. Por tratar-se de vigas, esses resultados, ainda que inferiores aos apresentados pelos sarrafos, chamam mais a atenção e preocupam, dada a função de maior importância das peças principais em relação às secundárias nas estruturas de madeira. Destacam-se os resultados apresentados pelos sarrafos, que obtiveram $100 \%$ de reprovação em relação à área mínima, e $89 \%$ de reprovação no quesito espessura mínima, o que significa que não se encontram sarrafos no Distrito Federal de acordo com a norma NBR 7190.

Dimensões de peças para uso geral (NBR 14807)

As medições coletadas foram confrontadas com as dimensões estabelecidas pela norma NBR 14807. Nessa comparação, 31,2\% das peças foram reprovadas. Nessa norma, a ABNT abandona a nomenclatura "vigota" e acrescenta outras: pranchinha, ripão, pontalete e quadradinho. No entanto, a coleta de dados foi realizada com base nas nomenclaturas propostas pela norma NBR 7203. Portanto, foram consideradas, para efeito de comparação, apenas as peças com nomenclaturas idênticas em ambas as normas. Pode-se observar uma evolução da norma analisada em relação à norma NBR 7203. Ambas especificam dimensões para nomenclaturas de peças de madeira, porém a NBR 14807 deixa claro que a escolha da bitola seja livre, desde que respeitados os intervalos de valores estabelecidos, ao contrário da NBR 7203, que primeiramente fixa as dimensões relativas a cada nomenclatura e em seguida estabelece "dimensões padrões" a serem produzidas em cada classe de peça.

\section{Conflito entre normas}

Pode-se observar que as três diferentes normas que abordam o tema madeira serrada entram em contradição ao especificar dimensões para uma mesma nomenclatura de peças. Isso é observado entre as normas NBR 7203, de 1982, e NBR 14807, de 2002, que divergem nas dimensões designadas para pranchão, prancha, viga, tábua, sarrafo e ripa, e na NBR 7190, dessa vez em relação à dimensão mínima de caibros e sarrafos mencionados pela norma NBR 14807 e a todas as espessuras mínimas de peças em comum com a NBR 7203 (Tabela 4).

Tabela 4. Comparação de dimensões e nomenclaturas entre as normas da ABNT.

Table 4. Comparison between dimensions and pieces names according to ABNT standards.

\begin{tabular}{lccc}
\hline & & Normas \\
\hline Peças & NBR 7203/1982 & NBR 7190/1997 & NBR 14807/2002 \\
Pranchão & Esp $(\mathrm{cm}) / \operatorname{Larg}(\mathrm{cm})$ & Espessura mínima $(\mathrm{cm})$ & Esp $(\mathrm{cm}) / \operatorname{Larg}(\mathrm{cm})$ \\
Prancha & $>7,0 />20,0$ & não especificado & $7,1-16,1 />16,1$ \\
Viga & $4,0-7,0 />20,0$ & não especificado & $3,9-7,0 />16,1$ \\
Vigota & $>4,0 / 11,0-20,0$ & 5 & $4,0-8,0 / 8,1-16,0$ \\
Caibro & $4,0-8,0 / 8,0-11,0$ & 5 & não especificado \\
Tábua & $4,0-8,0 / 5,0-8,0$ & 2,5 & $4,0-8,0 / 5,0-8,0$ \\
Sarrafo & $1,0-4,0 />10,0$ & não especificado & $1,0-3,7 />10,0$ \\
Ripa & $2,0-4,0 / 2,0-10,0$ & 2,5 & $2,1-3,9 / 2,0-9,9$ \\
& $<2,0 /<10,0$ & não especificado & $1,0-2,0 / 2,0-5,0$ \\
\hline
\end{tabular}

Essas divergências de dimensões e nomenclaturas observadas entre as normas da ABNT vão na contramão do processo de incentivo à normalização. Para os proprietários que desejam seguir as normas da $\mathrm{ABNT}$, fica a dúvida de qual seguir. É sensato pensar que a norma mais recente deva ser a correta, porém, segundo a ABNT, todas as normas em questão são válidas atualmente. De fato, a NBR 14807 é 
mais completa do que a NBR 7203 e condiz mais com a realidade de nomenclaturas encontradas neste estudo, no entanto os resultados revelam que nenhuma das duas é largamente difundida.

\section{A normalização em foco}

Foi averiguada a opinião de empresários e gerentes em relação à normalização de dimensões (bitola), do teor de umidade e da nomenclatura de peças, para a madeira serrada comercializada no Distrito Federal, e 76,6\% das empresas declararam-se a favor. Alguns empresários demonstraram um alto grau de interesse, justificando que a falta de regulamentação no setor abre brechas para uma concorrência desleal, que não respeita padrões de dimensões e não prima pela qualidade do produto.

Ao mesmo tempo em que a normalização é desejada pela maioria das empresas, apenas uma minoria sabe que ela já existe. Essa constatação permite inferir que a normalização não foi rejeitada pelos comerciantes. A normalização e seus benefícios gerados ainda sequer foram apresentados a essas pessoas ávidas por regularização. É evidente que, enquanto os consumidores não manifestarem de forma prioritária o interesse por produtos padronizados, estes não serão produzidos pelas empresas. Uma adesão em massa das empresas aos métodos normalizados depende primeiramente de ela ter ocorrido entre os consumidores. Sendo assim, a ABNT deveria dar especial atenção à publicidade dessa parte.

Diante dos resultados obtidos com a verificação de aplicação de normas da ABNT no setor de madeira serrada do Distrito Federal, a constatação que fica é a de que a ABNT não alcançou seus objetivos. As normas são criadas, porém são desconhecidas entre comerciantes e consumidores. Dividindo a responsabilidade da baixa popularidade das normas da ABNT entre comerciantes, consumidores e a própria $\mathrm{ABNT}$, pode-se lembrar que na grande maioria das vezes os responsáveis pela escolha das bitolas das peças em uma construção são os projetistas. No caso, eles representam os consumidores.

Em estudo sobre a normalização do setor produtivo de materiais de construção, Mascaró (1975) afirmou que os projetistas não só desconhecem o trabalho realizado pela ABNT como também mantêm uma atitude de reserva ante o uso e aplicação das normas. Talvez seja mais correto compreender que o maior responsável pela ignorância dos comerciantes, consumidores e projetistas em relação às normas seja a própria $\mathrm{ABNT}$.

Segundo Mascaró (1975), os institutos de normalização, muito ocupados (e preocupados) com suas tarefas específicas, esquecem que não só é necessário executar trabalhos de normalização, mas que também devem dedicar boa parte do seu tempo na divulgação do trabalho realizado. Porém, a autora acrescenta que outras instituições (academia, profissionais e industriais), na medida em que tenham compreendido a importância do tema, devem participar dessa tarefa de divulgação e informação. Um último aspecto deve ser considerado a respeito do cumprimento das normas da ABNT: a inexistência de uma fiscalização que coíba as práticas que estejam em desacordo com o proposto. Simplesmente não existe e nunca existiu fiscalização alguma, seja ela punitiva ou educativa. O problema é que as normas não possuem a força de uma lei e, portanto, não são obrigatórias. Seguir as normas torna-se apenas um atrativo, um selo de qualidade, para empresários que buscam atingir uma clientela mais consciente e exigente.

O cumprimento das normas da ABNT em uma determinada empresa só se torna obrigatório quando ela pretende participar de obras públicas, conforme a Lei $\mathrm{n}^{\circ} 4.150$, de 21 de novembro de 1962. Outra exceção são as empresas que visam exportação. Sabedores das exigências do mercado externo em relação à qualidade, essas empresas buscam o selo da ABNT com a convicção de que, ao optarem por tais métodos, estão investindo em qualidade e garantindo a aceitação de seus produtos nos países desenvolvidos.

\section{CONCLUSÕES E RECOMENDAÇÕES}

- Dentre as 18 espécies identificadas como madeira serrada estrutural no Distrito Federal, o angelimvermelho foi a mais comercializada, provavelmente em função de seu menor preço em comparação a outras espécies.

- Metade das empresas já registraram reclamações de clientes em relação à madeira serrada, sendo a insatisfação mais comum referente a medidas imprecisas e bitolas inadequadas. 
- Quase 27\% das empresas identificam erroneamente as espécies botânicas das peças de madeira serrada que comercializam, devido ao desconhecimento do nome científico.

- O armazenamento dos estoques de madeira serrada é inadequado em 33\% das empresas do Distrito Federal.

- Os padrões de bitola sugeridos pela norma NBR 7203 são ignorados por quase $87 \%$ das empresas.

- As normas NBR 7203, NBR 7190 e NBR 14807 da ABNT divergem entre si ao estipular nomenclaturas e dimensões de madeira serrada, o que gera grande confusão para o setor industrial.

- A maioria das madeireiras do Distrito Federal é favorável à normalização do setor, o que demonstra que o setor está preocupado com essa questão.

Recomenda-se que os empresários do setor madeireiro do Distrito Federal adotem as normas da ABNT como princípio de metodologia na produção de peças de madeira serrada. Além disso, procurem acompanhar as atualizações de normas e de técnicas que acrescentem qualidade ao produto final. Recomenda-se à ABNT revisar as informações conflitantes contidas nas normas NBR 7203, NBR 7190 e NBR 14807, ou simplesmente invalidar as normas que estejam desatualizadas. Recomenda-se ainda à ABNT que intensifique os esforços de divulgação de seus trabalhos, realizando campanhas informativas entre comerciantes, academia, profissionais e consumidores em geral.

\section{REFERÊNCIAS}

ASSOCIAÇÃO BRASILEIRA DE NORMAS TÉCNICAS (ABNT). NBR 7203/1982: madeira serrada e beneficiada. Rio de Janeiro, 1982.

ASSOCIAÇÃO BRASILEIRA DE NORMAS TÉCNICAS (ABNT). NBR 7190/1997: projeto de estruturas de madeira. Rio de Janeiro, 1997.

ASSOCIAÇÃO BRASILEIRA DE NORMAS TÉCNICAS (ABNT). NBR 14807/2002: peças de madeira serrada: dimensões. Rio de Janeiro, 2002.

ATANASOV, A. Investindo em qualidade. Curitiba/PR. Revista da Madeira, 2001.

CAMARGOS, J. A. A.; CORADIN, V. T. R.; CZARNESKI, C. M.; OlIVEIRA, D.; MEGUERDITCHIAN, I. Catálogo de árvores do Brasil. Brasília, DF: IBAMA, 2001.

DEL MENEZZI, C. H. S.; BONDUELLE, G. M. Diagnóstico do controle de qualidade na indústria da madeira e do mobiliário do distrito federal. Floresta, Curitiba, v. 33, n. 1, p. 76-86. 2002.

GALVÃO, A. P. M.; JANKOWSKY, I. P. Secagem racional da madeira. São Paulo: Nobel, 1988.

GESUALDO, F. A. R. Estruturas de madeira: notas de aula. Uberlândia: Universidade Federal de Uberlândia, 1998, 80 p.

INSTITUTO BRASILEIRO DO MEIO AMBIENTE E DOS RECURSOS NATURAIS RENOVÁVEIS (IBAMA). Madeiras da Amazônia: características e utilização. Brasília, DF, 1997. v. 3.

INSTITUTO BRASILEIRO DE DESENVOLVIMENTO FLORESTAL (IBDF). Madeiras da Amazônia: características e utilização. Brasília,DF, 1988. v.12.

INSTITUTO BRASILEIRO DE DESENVOLVIMENTO FLORESTAL (IBDF). Madeiras da Amazônia: características e utilização. Brasília, DF, 1981. v. 11.

MASCARÓ, L. A. R. Caracterização do setor produtivo de materiais de construção. São Paulo: Universidade de São Paulo, 1975. (Cadernos de Pesquisa).

PIO, N. S.; CAVALVANTI, M. A.; OLIVEIRA, L. B.; BARROS, S. S. Estudo crítico das normas de classificação de madeira e seu uso nas serrarias do estado do amazonas. Manaus/AM. Revista da Madeira, Curitiba, 2004.

REVISTA DA MADEIRA. Curitiba. Associação Brasileira dos Produtores de Madeira. Ano 16, n. 94. 2006. 